\title{
Current concepts on the use and adhesive bonding of glass-fiber posts in dentistry: a review
}

\author{
Aline Pinheiro de Moraes, Maximiliano Sérgio Cenci, Rafael Ratto de Moraes and Tatiana Pereira-Cenci*
}

\author{
* Correspondence: \\ tatiana.cenci@ufpel.tche.br \\ Graduate Program in Dentistry, \\ Federal University of Pelotas, Rua \\ Gonçalves Chaves 457, 96015-560 \\ Pelotas, RS, Brazil
}

\begin{abstract}
The aim of this study was to review and summarize the in vitro and clinical data on the use of glass-fiber posts concerning recent changes in the philosophy, materials, and technology that have impacted significantly the art and science of endodontic post placement. Original scientific papers or reviews listed in the Medline or ISI Web of Science databases from 1981 to 2013 were searched electronically using the following key words: endodontically-treated teeth, glass-fiber post, dentistry, resin cement, silane, and adhesive. The literature supports the use of a post when the remaining coronal structure is insufficient to provide retention for the restoration. Concerning which post to select, glass-fiber posts offer two important advantages: the elastic modulus is similar to that of dentin, and these posts and the respective core build-ups are cemented by an adhesive technique. However, some issues remain unclear. Randomized controlled trials are needed to confirm whether the use of silane influences the bonding and whether self-adhesive resin cements constitutes a reliable clinical option. Overall, the use of fiber posts is an important clinical option in dentistry, but clinicians should be aware of the difficulties in achieving good adhesion within the root canal.
\end{abstract}

Keywords: Adhesion; Bonding; Dentistry; Glass-fiber posts; Review

\section{Introduction}

Intra-radicular posts have been used to provide anchorage for dental restorations for over 250 years [1]. In the past decades, the increasing demand for aesthetics has led to the development of metal-free post-and-core systems, especially fiber-reinforced epoxy posts. To ensure a successful aesthetical outcome, the post-and-core system needs to be tooth-colored, reflecting and transmitting light similarly to a natural tooth $[2,3]$. Fiber posts have been developed to improve the optical effects of aesthetic restorations $[4,5]$ and are widely used for restoring endodontically-treated teeth with insufficient coronal tooth structure as a core for the restoration [6,7]. The use of posts in cases in which the tooth structure has been destroyed due to caries, trauma, or overaggressive endodontic procedures is gaining widespread acceptance among dental clinicians $[8,9]$.

Together with the increased use of pre-fabricated posts, especially fiber posts, an increase has also been observed in the number of publications on this subject, testing different cementation protocols, adhesive systems, and cements and discussing the indications for posts' use and the problems currently found in clinical practice. All this information should be revised and summarized to educate the dental practitioner about the current concepts and evidence for the use of fiber posts, in order to achieve

(c) 2013 Moraes et al.; licensee Springer. This is an open access article distributed under the terms of the Creative Commons Attribution License (http://creativecommons.org/licenses/by/2.0), which permits unrestricted use, distribution, and reproduction in any medium, provided the original work is properly cited. 
the best results with the technique. Thus, the aim of this review was to discuss the current concepts for the use of glass-fiber posts (GFPs) as well as the problems that may interfere with their adhesive bonding within the endodontic post space. Knowledge and control of factors affecting the posts' bond strength to root canals may ultimately improve the clinical performance of GFP-retained restorations.

\section{Review}

Original scientific papers or reviews listed in the Medline or ISI Web of Science databases from 1981 to 2013 were searched electronically using the following key words: endodontically-treated teeth, glass-fiber post, dentistry, resin cement, silane, and adhesive. Papers published in all languages were selected, and the most up-to-date or relevant references were chosen. Additionally, the cross-referencing of important papers identified those of historical value, which were also selected. Although papers written in all languages were considered, all the relevant studies were written in the English language. In order to discuss each item from the clinical use perspective, the results from the literature search were divided into the following six subcategories: reasons for the use of posts in dentistry; post selection criteria: glass-fiber posts; bonding systems; luting agents; post surface treatments; and critical clinical points.

\section{Reasons for use of posts in dentistry}

One of the main reasons for the use of posts is that they are incorrectly believed to reinforce the tooth structure. The development of epoxy posts reinforced with glassfibers derived from a need to minimize the mismatch among the elastic modulus of the post, luting agent, core material, and tooth. Fiber posts, although not actually reinforcing the tooth structure, may generate a more homogeneous stress distribution at the bonding assembly than rigid posts [10] (such as metal or zirconia posts) and thus may reduce the risk of root fractures. The potential risk is further reduced by the chemical bonding that occurs between the post and the luting cement. In addition to the favorable physical properties of GFPs, light can sometimes be transmitted through this type of post, allowing the light activation of photopolymerizable adhesive materials in the confines of the root canal [11].

The amount of remaining tooth structure after endodontic treatment or caries removal is a significant factor in determining the possibility of tooth fracture $[12,13]$. Posts are used to provide retention of the core material; whether and what kind of a post is needed depends on the remaining dental structure [14]. The literature suggests that the use of fiber posts and resin composite cements might reduce the occurrence of root fractures or post debonding [15]. In general, when the remaining coronal structure is insufficient to provide retention of the restoration, the use of an intraradicular post is indicated.

\section{Post selection criteria: glass-fiber posts}

In many long-term clinical studies, cast metal posts have shown good adaptability to the configuration and angulation of root canal walls as well as an ideal connection to the metal core, with no possibility of separation [1]. However, cast metal posts and cores are associated with inferior aesthetics because they do not allow light 
transmission. Other limitations include the risks that metal posts might corrode, causing gingival and tooth discoloration [1]; might be associated with possible biocompatibility concerns [16]; might trigger allergic reactions [17]; might offer less retention; and might lead to serious types of root fractures [18]. In addition, metal posts have low resilience and do not match the elastic modulus of the tooth structure [19].

Although carbon fiber posts were introduced as an alternative to metal posts, limitations as radiolucency, masking difficulty given all-ceramic or composite restorations, and stiffness similar to that of metal posts $[20,21]$ led to their replacement with white and translucent GFPs, which produce better aesthetic results [22]. Thus, GFPs have become a realistic alternative to overcome these drawbacks and are probably the most widely used and studied type of posts in dentistry [3,20,23].

Two different types of fiber-reinforced epoxy posts can be used as post-and-core systems: customized and prefabricated posts. Customized post-and-core build-ups commonly involve the use of glass or polyethylene fiber-reinforced posts that are luted directly into the root canal [24]. Prefabricated fiber posts consist of fibers either of carbon, quartz, silica, zirconia, or glass [25] embedded in an epoxy resin component with a silane coupling agent binding the fibers and resin together. Posts comprised of a mix between glass and carbon fibers are also available [26].

Retrospective $[24,27,28]$ and prospective $[29,30]$ clinical studies have testified to the overall satisfactory performance of endodontically-treated teeth restored with fiber post-and-core systems. An important clinical remark is that the fracture of rigid posts can result in tooth loss, because it is nearly impossible to remove their apically-fixed part [31]. Fiber posts are easier to remove without the risk of root perforation because they can be burned out [32].

Prefabricated GFPs are made up of glass-fibers embedded in a resin matrix and may also contain inorganic particles [33]. The fibers are pre-stressed, and, subsequently, the resin is injected under pressure to fill the spaces between the fibers, giving them solid cohesion. In most posts, epoxy resin or its derivatives are the main component of the organic phase. It has been suggested the epoxy resin may attach to methacrylate-based resin and composites through common free radicals [4], which would allow cementation using adhesive resin cements [11,34]. However, it has also been suggested that the polymer matrix of the posts is virtually non-reactive, because the resin has a high degree of conversion and is highly crosslinked [35]. In this case, the adhesive cementation of GFPs relies on the bonding of the silane coupling agent to the inorganic glass-fibers.

The advantages of GFPs cited in the introduction have contributed to their popularity. An additional advantage of GFPs is that they are readily retrievable after failure [36]. An in vitro study intimated that fiber posts are less likely to cause vertical root fractures than stainless steel posts [37]. Forces in the tooth restored with a fiber post are distributed to the restored complex in a manner that does not put stress on the vulnerable root structure [4]. A finite element analysis also showed that a GFP resulted in the lowest stress generation inside the root because the stiffness of the post is similar to that of dentin [38], whereas a metal post-andcore system transferred higher stresses to the root, which might cause a higher incidence of vertical root fractures. Hence, two important characteristics of GFPs are that (i) their elastic modulus is similar to that of dentin [20] and that (ii) these posts and the respective core build-ups are cemented with an adhesive technique 
[39]. These characteristics may improve the retention and mechanical performance of the restored teeth [33].

The use of GFPs still presents several difficulties. Bonding to intraradicular dentin is challenging for clinicians due to the complexity and sensitivity of the technique $[40,41]$. Because various resin cements and adhesives are used in clinical practice, it is imperative to know how they perform in relation to incompatibilities between adhesives and resin cements [42], which can lead to possible clinical failures.

\section{Bonding systems}

The need for the adhesive luting of GFPs has engendered debates [41,43]. It has been reported that the bonding of GFPs to the dental structure may be related more to the friction of the post along the canal walls than to the adhesive bonding to root dentin [41]. The use of resin cements, however, has been found to significantly increase the retention of fiber posts and improve the fracture resistance of the bonded structures when compared to other cements [33,44-47]. Adhesive cementation has also been shown to better withstand functional forces [43], improve marginal adaption with better apical sealing [48], increase retention with reduced post length [49], and optimize the fracture patterns in case of failures [50]. Therefore, the adhesive cementation of GFPs is preferred over non-adhesive luting.

Adhesion between resin and dentin is considered to be a weak point in the bonded assembly. The type of adhesive system used in association with the resin cement is of great importance. Current adhesive systems can react with the dental structures by either etchand-rinse or self-etch approaches. In the former, micromechanical interlocking with the root dentin is obtained by a conditioning step using phosphoric acid followed by the application of a bonding solution. The latter approach uses non-rinse acidic monomers that simultaneously condition, prime, and infiltrate the dentin, resulting in adhesion by shallow hybridization with residual hydroxyapatite.

The presence of a thick endodontic smear layer has prompted researchers to recommend a preliminary etching step to remove debris from the canal walls and increase post retention [51-53]. Acid application might also dissolve the residual canal sealer [54], although the possibility of over-etching the dentin is a potential shortcoming of etch-andrinse systems [55]. Some studies have demonstrated similarities between bond strengths for self-etch and etch-and-rinse adhesives in different regions of coronal dentin [56-59]. One study showed that a self-etch system may create a better bond to the cervical, middle, and apical thirds of the radicular dentin than an etch-and-rinse adhesive [60]. The difficulty in removing the smear layer may be a disadvantage of self-etch materials $[51,61]$.

Numerous authors have reported that GFP cementation with the resin cement associated with etch-and-rinse adhesive may generate greater bonding potential than selfetch adhesive [51,61-64]. This result may be explained by the fact that the acidic monomers responsible for substrate conditioning in self-etch adhesives are less effective in etching the dental structure than the phosphoric acid used in the etch-and-rinse approach. The etch-and-rinse strategy, however, requires a wet dentin substrate for optimal bonding [65], and controlling the humidity within the root canal is critical. Because the self-etch approach does not require moisture control after etching, these systems can potentially simplify the technique. 
Irrespective of the type of bonding agent, limited access to curing light within the root canal may hinder the photopolymerization of the adhesives. Studies show higher bond strengths [66] and improved hybridization along the root canal [67] for self or dual-polymerized adhesives. One study also showed that the use of a self-activating adhesive combined with a dual-cure regular cement enabled the effective luting of GFPs, regardless of the amount of light transmitted through the post [68]. Therefore, the use of dual-cured adhesives seems preferable, although other investigations suggest that the use of self-cure activators might not enhance the bond strengths of GFP to root canals $[60,69]$. In order to optimize the outcome of cementation procedures, the bonding system used by the clinician should be known thoroughly, and the clinical steps need to be strictly followed.

\section{Luting agents}

Contemporary resin cements may be classified into two main groups, according to the adhesive approach. In the first group (regular resin cements), the cement is used in association with an adhesive system, while in the second group (more recently introduced) the cement is self-adherent, i.e., no pre-treatment of the dental substrate using acid or primers is necessary, allowing simultaneous bonding between the intraradicular dentin and post. These latter materials are known as self-adhesive (or self-etching) resin cements and may simplify the adhesive luting procedures.

The bond properties of self-adhesive resin cements are based upon acidic functional methacrylate that may simultaneously demineralize and infiltrate the tooth substrates [70], with the additional potential to chemically bond to hydroxyapatite [71]. Studies have reported, however, limited etching potential for self-adhesive cements compared to etchand-rinse and self-etch adhesives when luting GFPs [62,72-74], with one investigation showing the similar bonding potentials of the combination regular resin cement-self-etch adhesive and of a self-adhesive resin cement [51]. Self-adhesive cements may also present lower degrees of $C=C$ conversion [75] and poorer mechanical properties [76] than regular resin cements. The lower etching aggressiveness and suboptimal properties may account for the low early (immediate) interfacial strengths reported for GFPs luted with self-adhesive cements [77]. Nonetheless, in a 3-year randomized controlled clinical trial, a self-adhesive resin cement performed well with GFPs; this finding was confirmed in a 5-year simulated clinical function and subsequent linear loading [78].

Resin cements may also be classified according to their polymerization mode as photopolymerized, self-polymerized, or dual-polymerized materials. Photocured cements cannot be used for post cementation because they need the curing light to penetrate into the bulk of the material; conversely, self-cured (or chemically-cured) cements have no problems related to their polymerization in the apical areas because the curing process is initiated by a redox mechanism, which is triggered upon the mixing of the base and catalyst pastes. Self-cured materials, however, offer worse handling characteristics due to their relatively fast, uncontrolled polymerization.

Dual-cured resin cements are mostly used for luting GFPs. There materials theoretically combine the favorable properties of extended working time and the capability of reaching proper polymerization in either the presence or absence of light. It has been demonstrated, however, that the attenuated light penetration interferes 
with the cement polymerization toward the apical areas of the root canal [79-81], sometimes even when translucent fiber posts are used [82]. In general, the selfcure mechanism for dual-cured materials alone is not only slower but also less effective than the use of light-activation [83-85].

It is also known that self or dual-cured resins cements are not compatible with simplified adhesives (i.e., two-step etch-and-rinse or one-step self-etch agents). This incompatibility is due to the low $\mathrm{pH}$ of simplified adhesives, which may react to the basic tertiary amines used as self-cure co-initiators, interfering with proper polymerization [42]. Thus, non-simplified adhesives (three-step etch-and-rinse systems, for instance) should be used for bonding GFPs to root canals using regular resin cements.

The recent introduction of self-adhesive cements has allowed the luting of GFPs using a simpler approach, potentially reducing the technique sensitivity. In such a situation, the clinician should focus more on the preparation of the canal for the post and not rely on the cement itself. The limited etching capability of self-adhesive materials in the presence of the compact smear layer created within the endodontic space [74] may still be a matter of concern. In most clinical investigations, GFPs were cemented using etch-and-rinse adhesives in combination with regular self-cured $[27,86]$ or dual-cured $[9,27,87-89]$ resin cements. Therefore, up to now, clinical studies showing the clinical performance of adhesively luted posts using self-adhesive cements (or even self-etch primers) are scarce, despite the number of recent laboratory investigations showing good results for self-adhesive resin cements [90-93]. The results of a recent systematic review and meta-analysis of in vitro studies suggest that the use of selfadhesive resin cement could improve the retention of glass-fiber posts as compared with regular resin cements [94]. Self-adherent materials are gaining fast popularity and may represent a reliable clinical option as soon as more clinical trials indicate results comparable to regular resin cements.

\section{Post surface treatments}

Various pretreatment procedures, such as silanization, acid etching, sandblasting, tribochemical silica coating, and the application of bonding agents are currently being investigated for enhancing the bond strength of GFPs to the luting cement [95-98]. Other treatments as plasma and dopamine treatment have also been described, with varying results $[99,100]$. Silanization is the technique used most often to achieve this goal. Silane coupling agents are bifunctional molecules, with one end of the molecule capable of reacting with inorganic glass-fiber and the other with organic resin [101].

The action mechanism of silanes relies on the formation of bonds between its functional alkoxy groups and the $\mathrm{OH}$-covered inorganic fibers. Improvement in the post surface wettability is another effect of silanization. The highly crosslinked polymer matrix of GFPs is virtually non-reactive [102,103]; therefore, only the exposed fibers on the post surface could provide sites for chemical bonding with the silane molecules. The silane coupling agent most commonly used for dental applications is a pre-hydrolyzed monofunctional $\gamma$-methacryloxypropyltrimethoxysilane diluted in an ethanol-water solution.

The use of silanes to improve the bonding of resin luting agents to GFP is, however, a controversial topic [4]. Some studies reported that silanization does not have a 
significant effect on bond strengths of resin cements to GFPs $[4,97,104]$, whereas others reported an increasing effect on bond strengths via silanization [105]. Silane coating of GFPs has also shown to increase the post-core bond strength and permit a more uniform adaptation of the composite core to the post [106]. A recent investigation has also demonstrated that the application of bonding solutions, especially combined with silane coupling agents, improves the bond strength of resin cement to the post surface [107]. However, randomized controlled trials are needed to confirm whether the use of silane influences the bond strength of GFPs.

\section{Critical clinical points}

Various factors may compromise the longevity of root-post-core-crown systems, such as humidity control inside the root canal [15]; anatomic variation and cavity configuration [41], which may lead to a non-homogeneous application of the etching and bonding procedures; incomplete cement polymerization in deeper root canal areas because of lack of light penetration, even with dual-cure cements [80]; chemical incompatibility between simplified adhesives and self or dual-cured cements [42]; and the design, length, and thickness of the post, cementation, and the quantity of remaining tooth substance [108].

Many combinations of different adhesive systems and resin cements can be used for post cementation. Adhesive procedures are technically sensitive, and the root canal environment is subjected to a number of variables that may directly affect bond strength [66]. Several factors have been described to affect the intraradicular bonding of resinbased materials $[19,109]$. The histological characteristics of root dentin [40]; the presence of primary and secondary endodontic smear layers created either by endodontic instruments and modified by irrigants or by post-space calibrated burs [110]; negative clinical factors, i.e., minimal residual dentin structure; and adverse geometric factors [54] are consistent problems that affect bond strength within the endodontic space.

Up to now, most failures involving endodontically-treated teeth restored with fiber posts have occurred through debonding $[8,51,111]$ due to stress concentration between the cement and post [112]. However, it should be highlighted that these failures are mostly reported in vitro, and may not represent what takes place in the actual clinical situation. Clinical trials dealing with GFPs usually report post debonding, traumatic post fracture, and core build-up failure with fracture of the core/tooth as the most common reasons for failure $[9,113]$. The difficulty with some fiber posts is the crosslinked nature of the polymer matrix, which makes it harder for the composite resin to bond to the post $[102,103]$. Yet, in most cases, the failure is not between cement and post, but between cement/adhesive and dentin.

The bond strength between the resin luting agent and post-space dentin is influenced by the distribution of resin cement in the coronal, middle, and apical third of the root during the luting procedure and by the anatomic and histologic characteristics of the root canal, including the orientation of dentin tubule [114-117]. This circumstance is probably due to the limited ability of light to diffuse along the entire length of the resin cement, thus compromising the polymerization of the cement in the most apical regions [82,117]. Additionally, it is difficult to control for moisture and adhesive application toward the apical region of the canal [118]. 
Moreover, the apical third of the root canal is the location where most of the smear layer, debris, and sealer/gutta-percha residues are found after post space preparation and acid etching [54]. The bond strength between resin cements and root dentin is generally reported to be very low. Despite the fact that current dental adhesive approaches vary in dentin bonding ability [119], low bond strength values may not be capable of overcoming the shrinkage stresses generated during the polymerization of the resin luting agent, as a thin layer of curing resin with limited free surface for stress relief creates an undesirable scenario when C-factor is a concern [120].

\section{Conclusions}

Overall, it can be concluded from this review that the use of GFPs in clinical practice seems to be recommended to improve the retention of restorations and complete crowns in cases of great loss of tooth structure. However, in order to obtain the best results with GFP anchorage, clinicians should be aware of the difficulties in achieving good adhesion within the root canal. Clinicians should also pay attention to the selection of materials, and the manufacturers' recommendations should be thoroughly followed. More clinical research should be conducted to find out the influence of remaining tooth structure, i.e., the number of remaining walls, on the clinical performance of GFP-retained restorations. Also, state-of-the-art techniques, mainly concerning the use self-adhesive cements and silane for improving GFP retention to root canal, should be explored in future studies.

\section{Competing interests}

The authors declare that they have no competing interests.

\section{Authors' contributions}

APM conducted the literature search. All authors helped to draft the manuscript. All authors read and approved the final manuscript.

Received: 31 July 2013 Accepted: 23 August 2013

Published: 23 December 2013

References

1. Stewardson DA (2001) Non-metal post systems. Dent Update 28:326-332, 334, 336

2. Michalakis KX, Hirayama H, Sfolkos J, Sfolkos K (2004) Light transmission of posts and cores used for the anterior esthetic region. Int J Periodontics Restor Dent 24:462-469

3. Paul SJ, Werder P (2004) Clinical success of zirconium oxide posts with resin composite or glass ceramic cores in endodontically treated teeth: a 4-year retrospective study. Int J Prosthodont 17:524-528

4. Perdigao J, Gomes G, Lee IK (2006) The effect of silane on the bond strengths of fiber posts. Dent Mater 22:752-758

5. Demiryurek EO, Kulunk S, Sarac D, Yuksel G, Bulucu B (2009) Effect of different surface treatments on the push-out bond strength of fiber post to root canal dentin. Oral Surg Oral Med Oral Pathol Oral Radiol Endod 108:e74-e80

6. Assif D, Gorfil C (1994) Biomechanical considerations in restoring endodontically treated teeth. J Prosthet Dent 71:565-567

7. Morgano SM, Brackett SE (1999) Foundation restorations in fixed prosthodontics: current knowledge and future needs. J Prosthet Dent 82:643-657

8. Aksornmuang J, Foxton RM, Nakajima M, Tagami J (2004) Microtensile bond strength of a dual-cure resin core material to glass and quartz fibre posts. J Dent 32:443-450

9. Naumann M, Blankenstein F, Dietrich T (2005) Survival of glass fibre reinforced composite post restorations after 2 years-an observational clinical study. J Dent 33:305-312

10. Silva NR, Castro CG, Santos-Filho PC, Silva GR, Campos RE, Soares PV, Soares CJ (2009) Influence of different post design and composition on stress distribution in maxillary central incisor: Finite element analysis. Indian J Dent Res 20:153-158

11. Ferrari M, Vichi A, Grandini S (2001) Efficacy of different adhesive techniques on bonding to root canal walls: an SEM investigation. Dent Mater 17:422-429

12. Lloyd PM, Palik JF (1993) The philosophies of dowel diameter preparation: a literature review. J Prosthet Dent 69:32-36

13. Tjan AH, Whang SB (1985) Resistance to root fracture of dowel channels with various thicknesses of buccal dentin walls. J Prosthet Dent 53:496-500 
14. Peroz I, Blankenstein F, Lange KP, Naumann M (2005) Restoring endodontically treated teeth with posts and cores-a review. Quintessence Int 36:737-746

15. Boschian Pest L, Cavalli G, Bertani P, Gagliani M (2002) Adhesive post-endodontic restorations with fiber posts: push-out tests and SEM observations. Dent Mater 18:596-602

16. Engelman MJ (1988) Core materials. J Calif Dent Assoc 16:41-45

17. Silness J, Gustavsen F, Hunsbeth J (1979) Distribution of corrosion products in teeth restored with metal crowns retained by stainless steel posts. Acta Odontol Scand 37:317-321

18. Torbjorner A, Karlsson S, Odman PA (1995) Survival rate and failure characteristics for two post designs. J Prosthet Dent 73:439-444

19. Schwartz RS, Robbins JW (2004) Post placement and restoration of endodontically treated teeth: a literature review. J Endod 30:289-301

20. Asmussen E, Peutzfeldt A, Heitmann T (1999) Stiffness, elastic limit, and strength of newer types of endodontic posts. J Dent 27:275-278

21. Vichi A, Ferrari M, Davidson CL (2000) Influence of ceramic and cement thickness on the masking of various types of opaque posts. J Prosthet Dent 83:412-417

22. Giachetti L, Grandini S, Calamai P, Fantini G, Scaminaci RD (2009) Translucent fiber post cementation using light- and dual-curing adhesive techniques and a self-adhesive material: push-out test. J Dent 37:638-642

23. Qualtrough AJ, Mannocci F (2003) Tooth-colored post systems: a review. Oper Dent 28:86-91

24. Piovesan EM, Demarco FF, Cenci MS, Pereira-Cenci T (2007) Survival rates of endodontically treated teeth restored with fiber-reinforced custom posts and cores: a 97-month study. Int J Prosthodont 20:633-639

25. Mannocci F, Sherriff M, Watson TF (2001) Three-Point Bend Test Fiber Posts J Endod 27:758-761

26. Spazzin AO, de Moraes RR, Cecchin D, Farina AP, Carlini-Junior B, Correr-Sobrinho L (2009) Morphological analysis of glass, carbon and glass/carbon fiber posts and bonding to self or dual-cured resin luting agents. J Appl Oral Sci 17:476-480

27. Ferrari M, Vichi A, Mannocci F, Mason PN (2000) Retrospective study of the clinical performance of fiber posts. Am J Dent 13:9B-13B

28. Fredriksson M, Astback J, Pamenius M, Arvidson K (1998) A retrospective study of 236 patients with teeth restored by carbon fiber-reinforced epoxy resin posts. J Prosthet Dent 80:151-157

29. Glazer B (2000) Restoration of endodontically treated teeth with carbon fibre posts-a prospective study. J Can Dent Assoc 66:613-618

30. Mannocci F, Bertelli E, Sherriff M, Watson TF, Ford TR (2002) Three-year clinical comparison of survival of endodontically treated teeth restored with either full cast coverage or with direct composite restoration. J Prosthet Dent 88:297-301

31. Martinez-Insua A, da Silva L, Rilo B, Santana U (1998) Comparison of the fracture resistances of pulpless teeth restored with a cast post and core or carbon-fiber post with a composite core. J Prosthet Dent 80:527-532

32. de Rijk WG (2000) Removal of fiber posts from endodontically treated teeth. J Dent 13:19B-21B

33. Mendoza DB, Eakle WS, Kahl EA, Ho R (1997) Root reinforcement with a resin-bonded preformed post. J Prosthet Dent 78:10-14

34. Sahmali S, Demirel F, Saygili G (2004) Comparison of in vitro tensile bond strengths of luting cements to metallic and tooth-colored posts. Int J Periodontics Restor Dent 24:256-263

35. Bell AM, Lassila LV, Kangasniemi I, Vallittu PK (2005) Bonding of fibre-reinforced composite post to root canal dentin. J Dent 33:533-539

36. Cormier CJ, Burns DR, Moon P (2001) In vitro comparison of the fracture resistance and failure mode of fiber, ceramic, and conventional post systems at various stages of restoration. J Prosthodont 10:26-36

37. Isidor F, Odman P, Brondum K (1996) Intermittent loading of teeth restored using prefabricated carbon fiber posts. Int J Prosthodont 9:131-136

38. Pegoretti A, Fambri L, Zappini G, Bianchetti M (2002) Finite element analysis of a glass fibre reinforced composite endodontic post. Biomaterials 23:2667-2682

39. Hsu YB, Nicholls JI, Phillips KM, Libman WJ (2002) Effect of core bonding on fatigue failure of compromised teeth. Int J Prosthodont 15:175-178

40. Ferrari M, Mannocci F, Vichi A, Cagidiaco MC, Mjor IA (2000) Bonding to root canal: structural characteristics of the substrate. Am J Dent 13:255-260

41. Goracci C, Fabianelli A, Sadek FT, Papacchini F, Tay FR, Ferrari M (2005) The contribution of friction to the dislocation resistance of bonded fiber posts. J Endod 31:608-612

42. Tay FR, Pashley DH, Yiu CK, Sanares AM, Wei SH (2003) Factors contributing to the incompatibility between simplified-step adhesives and chemically-cured or dual-cured composites. Part I. Single-step self-etching adhesive. J Adhes Dent 5:27-40

43. Naumann M, Sterzenbach G, Rosentritt M, Beuer F, Frankenberger R (2008) Is adhesive cementation of endodontic posts necessary? J Endod 34:1006-1010

44. Bonfante G, Kaizer OB, Pegoraro LF, do Valle AL (2007) Tensile bond strength of glass fiber posts luted with different cements. Braz Oral Res 21:159-164

45. Cohen BI, Pagnillo MK, Newman I, Musikant BL, Deutsch AS (1998) Retention of three endodontic posts cemented with five dental cements. J Prosthet Dent 79:520-525

46. Reis KR, Spyrides GM, Oliveira JA, Jnoub AA, Dias KR, Bonfantes G (2011) Effect of cement type and water storage time on the push-out bond strength of a glass fiber post. Braz Dent J 22:359-364

47. Schmitter M, Huy C, Ohlmann B, Gabbert O, Gilde H, Rammelsberg P (2006) Fracture resistance of upper and lower incisors restored with glass fiber reinforced posts. J Endod 32:328-330

48. Bachicha WS, DiFiore PM, Miller DA, Lautenschlager EP, Pashley DH (1998) Microleakage of endodontically treated teeth restored with posts. J Endod 24:703-708 
49. Nissan J, Dmitry Y, Assif D (2001) The use of reinforced composite resin cement as compensation for reduced post length. J Prosthet Dent 86:304-308

50. Salameh Z, Sorrentino R, Papacchini F, Ounsi HF, Tashkandi E, Goracci C, Ferrari M (2006) Fracture resistance and failure patterns of endodontically treated mandibular molars restored using resin composite with or without translucent glass fiber posts. J Endod 32:752-755

51. Goracci C, Sadek FT, Fabianelli A, Tay FR, Ferrari M (2005) Evaluation of the adhesion of fiber posts to intraradicular dentin. Oper Dent 30:627-635

52. Leirskar J, Nordbo H (2000) The effect of zinc oxide-eugenol on the shear bond strength of a commonly used bonding system. Endod Dent Traumatol 16:265-268

53. Zhang L, Huang L, Xiong Y, Fang M, Chen JH, Ferrari M (2008) Effect of post-space treatment on retention of fiber posts in different root regions using two self-etching systems. Eur J Oral Sci 116:280-286

54. Serafino C, Gallina G, Cumbo E, Ferrari M (2004) Surface debris of canal walls after post space preparation in endodontically treated teeth: a scanning electron microscopic study. Oral Surg Oral Med Oral Pathol Oral Radiol Endod 97:381-387

55. Hashimoto M, Ohno H, Kaga M, Sano H, Tay FR, Oguchi H, Araki Y, Kubota M (2002) Over-etching effects on micro-tensile bond strength and failure patterns for two dentin bonding systems. J Dent 30:99-105

56. Akagawa H, Nikaido T, Takada T, Burrow MF, Tagami J (2002) Shear bond strengths to coronal and pulp chamber floor dentin. Am J Dent 15:383-388

57. Kijsamanmith K, Timpawat S, Harnirattisai C, Messer HH (2002) Micro-tensile bond strengths of bonding agents to pulpal floor dentine. Int Endod J 35:833-839

58. Tanumiharja M, Burrow MF, Tyas MJ (2000) Microtensile bond strengths of seven dentin adhesive systems. Dent Mater 16:180-187

59. Toledano M, Osorio R, Ceballos L, Fuentes MV, Fernandes CA, Tay FR, Carvalho RM (2003) Microtensile bond strength of several adhesive systems to different dentin depths. Am J Dent 16:292-298

60. Akgungor G, Akkayan B (2006) Influence of dentin bonding agents and polymerization modes on the bond strength between translucent fiber posts and three dentin regions within a post space. J Prosthet Dent 95:368-378

61. Hayashi M, Okamura K, Wu H, Takahashi Y, Koytchev EV, Imazato S, Ebisu S (2008) The root canal bonding of chemical-cured total-etch resin cements. J Endod 34:583-586

62. Mazzoni A, Marchesi G, Cadenaro M, Mazzotti G, Di Lenarda R, Ferrari M, Breschi L (2009) Push-out stress for fibre posts luted using different adhesive strategies. Eur J Oral Sci 117:447-453

63. Radovic I, Mazzitelli C, Chieffi N, Ferrari M (2008) Evaluation of the adhesion of fiber posts cemented using different adhesive approaches. Eur J Oral Sci 116:557-563

64. Valandro LF, Filho OD, Valera MC, de Araujo MA (2005) The effect of adhesive systems on the pullout strength of a fiberglass-reinforced composite post system in bovine teeth. J Adhes Dent 7:331-336

65. Nakajima M, Kanemura N, Pereira PN, Tagami J, Pashley DH (2000) Comparative microtensile bond strength and SEM analysis of bonding to wet and dry dentin. Am J Dent 13:324-328

66. Boff LL, Grossi ML, Prates LH, Burnett LH Jr, Shinkai RS (2007) Effect of the activation mode of post adhesive cementation on push-out bond strength to root canal dentin. Quintessence Int 38:387-394

67. Abou-Id LR, Morgan LF, Silva GA, Poletto LT, Lanza LD, Albuquerque Rde C (2012) Ultrastructural evaluation of the hybrid layer after cementation of fiber posts using adhesive systems with different curing modes. Braz Dent J 23:116-121

68. Vichi A, Carrabba M, Goracci C, Ferrari M (2012) Extent of cement polymerization along dowel space as a function of the interaction between adhesive and cement in fiber post cementation. J Adhes Dent 14:51-57

69. Faria e Silva AL, Casselli DS, Ambrosano GM, Martins LR (2007) Effect of the adhesive application mode and fiber post translucency on the push-out bond strength to dentin. J Endod 33:1078-1081

70. Radovic I, Monticelli F, Goracci C, Vulicevic ZR, Ferrari M (2008) Self-adhesive resin cements: a literature review. J Adhes Dent 10:251-258

71. Gerth HU, Dammaschke T, Zuchner H, Schafer E (2006) Chemical analysis and bonding reaction of RelyX Unicem and Bifix composites-a comparative study. Dent Mater 22:934-941

72. Calixto LR, Bandeca MC, Clavijo V, Andrade MF, Vaz LG, Campos EA (2012) Effect of resin cement system and root region on the push-out bond strength of a translucent fiber post. Oper Dent 37:80-86

73. Gomes GM, Gomes OM, Reis A, Gomes JC, Loguercio AD, Calixto AL (2011) Regional bond strengths to root cana dentin of fiber posts luted with three cementation systems. Braz Dent J 22:460-467

74. Goracci C, Tavares AU, Fabianelli A, Monticelli F, Raffaelli O, Cardoso PC, Tay F, Ferrari M (2004) The adhesion between fiber posts and root canal walls: comparison between microtensile and push-out bond strength measurements. Eur J Oral Sci 112:353-361

75. Moraes RR, Boscato N, Jardim PS, Schneider LF (2011) Dual and self-curing potential of self-adhesive resin cements as thin films. Oper Dent 36:635-642

76. Saskalauskaite E, Tam LE, McComb D (2008) Flexural strength, elastic modulus, and pH profile of self-etch resin luting cements. J Prosthodont 17:262-268

77. Sadek FT, Goracci C, Monticelli F, Grandini S, Cury AH, Tay F, Ferrari M (2006) Immediate and 24-hour evaluation of the interfacial strengths of fiber posts. J Endod 32:1174-1177

78. Naumann M, Sterzenbac G, Alexandra F, Dietrich T (2007) Randomized controlled clinical pilot trial of titanium vs. glass fiber prefabricated posts: preliminary results after up to 3 years. Int J Prosthodont 20:499-503

79. Baena E, Fuentes M, Garrido M, Rodriguez J, Ceballos L (2012) Influence of post-cure time on the microhardness of self-adhesive resin cements inside the root canal. Oper Dent 37:548-556

80. Cerutti F, Acquaviva PA, Gagliani M, Ferrari M, Mangani F, Depero LE, Cerutti A (2011) Degree of conversion of dual-cure resins light-cured through glass-fiber posts. Am J Dent 24:8-12

81. Shadman N, Atai M, Ghavam M, Kermanshah H, Ebrahimi SF (2012) Parameters affecting degree of conversion of dual-cure resin cements in the root canal: FTIR analysis. J Can Dent Assoc 78:C53 
82. Roberts HW, Leonard DL, Vandewalle KS, Cohen ME, Charlton DG (2004) The effect of a translucent post on resin composite depth of cure. Dent Mater 20:617-622

83. Faria-e-Silva AL, Moraes RR, Ogliari FA, Piva E, Martins LR (2009) Panavia F: the role of the primer. J Oral Sci 51:255-259

84. Moraes RR, Faria-e-Silva AL, Ogliari FA, Correr-Sobrinho L, Demarco FF, Piva E (2009) Impact of immediate and delayed light activation on self-polymerization of dual-cured dental resin luting agents. Acta Biomater 5:2095-2100

85. Reges RV, Moraes RR, Correr AB, Sinhoreti MA, Correr-Sobrinho L, Piva E, Nouer PR (2008) In-depth polymerization of dual-cured resin cement assessed by hardness. J Biomater Appl 23:85-96

86. Mannocci F, Qualtrough AJ, Worthington HV, Watson TF, Pitt Ford TR (2005) Randomized clinical comparison of endodontically treated teeth restored with amalgam or with fiber posts and resin composite: five-year results. Oper Dent 30:9-15

87. Ferrari M, Cagidiaco MC, Grandini S, De Sanctis M, Goracci C (2007) Post placement affects survival of endodontically treated premolars. J Dent Res 86:729-734

88. Grandini S, Goracci C, Tay FR, Grandini R, Ferrari M (2005) Clinical evaluation of the use of fiber posts and direct resin restorations for endodontically treated teeth. Int J Prosthodont 18:399-404

89. Monticelli F, Grandini S, Goracci C, Ferrari M (2003) Clinical behavior of translucent-fiber posts: a 2-year prospective study. Int J Prosthodont 16:593-596

90. Amaral M, Rippe MP, Bergoli CD, Monaco C, Valandro LF (2011) Multi-step adhesive cementation versus one-step adhesive cementation: push-out bond strength between fiber post and root dentin before and after mechanical cycling. Gen Dent 59:e185-e191

91. Dimitrouli M, Geurtsen W, Luhrs AK (2012) Comparison of the push-out strength of two fiber post systems dependent on different types of resin cements. Clin Oral Invest 16:899-908

92. Leme AA, Coutinho M, Insaurralde AF, Scaffa PM, da Silva LM (2011) The influence of time and cement type on push-out bond strength of fiber posts to root dentin. Oper Dent 36:643-648

93. Silva RA, Coutinho M, Cardozo PI, Silva LA, Zorzatto JR (2011) Conventional dual-cure versus self-adhesive resin cements in dentin bond integrity. J Appl Oral Sci 19:355-362

94. Sarkis-Onofre R, Skupien JÁ, Cenci MS, de Moraes RR, Pereira-Cenci T (2013) The role of resin cement on bond strength of glass-fiber posts (GFPs) luted into root canals: a systematic review and meta-analysis of in vitro studies. Oper Dent, 10.2341/13-070-LIT

95. Balbosh A, Kern M (2006) Effect of surface treatment on retention of glass-fiber endodontic posts. J Prosthet Dent 95:218-223

96. Monticelli F, Osorio R, Toledano M, Goracci C, Tay FR, Ferrari M (2006) Improving the quality of the quartz fiber postcore bond using sodium ethoxide etching and combined silane/adhesive coupling. J Endod 32:447-451

97. Radovic I, Monticelli F, Goracci C, Cury AH, Coniglio I, Vulicevic ZR, Garcia-Godoy F, Ferrari M (2007) The effect of sandblasting on adhesion of a dual-cured resin composite to methacrylic fiber posts: microtensile bond strength and SEM evaluation. J Dent 35:496-502

98. Sahafi A, Peutzfeld A, Asmussen E, Gotfredsen K (2004) Effect of surface treatment of prefabricated posts on bonding of resin cement. Oper Dent 29:60-68

99. Ye H, Zhang Q, Sun K, Zhang J, Jiao Y, Zhou Y (2012) Aging effects of fiber post surface treatment with nonthermal plasma. Int J Prosthodont 25:509-511

100. Yavirach P, Chaijareenont P, Boonyawan D, Pattamapun K, Tunma S, Takahashi H, Arksornnukit M (2009) Effects of plasma treatment on the shear bond strength between fiber-reinforced composite posts and resin composite for core build-up. Dent Mater J 28:686-692

101. Matinlinna JP, Lassila LV, Ozcan M, Yli-Urpo A, Vallittu PK (2004) An introduction to silanes and their clinical applications in dentistry. Int J Prosthodont 17:155-164

102. Davis P, Melo LS, Foxton RM, Sherriff M, Pilecki P, Mannocci F, Watson TF (2010) Flexural strength of glass fibre-reinforced posts bonded to dual-cure composite resin cements. Eur J Oral Sci 118:197-201

103. Lastumaki TM, Lassila LV, Vallittu PK (2003) The semi-interpenetrating polymer network matrix of fiber-reinforced composite and its effect on the surface adhesive properties. J Mater Sci Mater Med 14:803-809

104. Bitter K, Meyer-Lueckel H, Priehn K, Kanjuparambil JP, Neumann K, Kielbassa AM (2006) Effects of luting agent and thermocycling on bond strengths to root canal dentine. Int Endod J 39:809-818

105. Albaladejo A, Osorio R, Papacchini F, Goracci C, Toledano M, Ferrari M (2007) Post silanization improves bond strength of translucent posts to flowable composite resins. J Biomed Mater Res B Appl Biomater 82:320-324

106. Monticelli F, Toledano M, Osorio R, Ferrari M (2006) Effect of temperature on the silane coupling agents when bonding core resin to quartz fiber posts. Dent Mater 22:1024-1028

107. Oliveira AS, Ramalho ES, Spazzin AO, Naves LZ, Moraes RR (2013) Influence of silane and solvated bonding agents on the bond strength to glass-fibre posts. Aust Endod J, doi:10.1111/j.17474477.2011.00337.x

108. Sorensen JA, Martinoff JT (1984) Intracoronal reinforcement and coronal coverage: a study of endodontically treated teeth. J Prosthet Dent 51:780-784

109. Schwartz RS (2006) Adhesive dentistry and endodontics. Part 2: bonding in the root canal system-the promise and the problems: a review. J Endod 32:1125-1134

110. Schwartz RS, Fransman R (2005) Adhesive dentistry and endodontics: materials, clinical strategies and procedures for restoration of access cavities: a review. J Endod 31:151-165

111. Vichi A, Grandini S, Davidson CL, Ferrari M (2002) An SEM evaluation of several adhesive systems used for bonding fiber posts under clinical conditions. Dent Mater 18:495-502

112. Bolhuis P, de Gee A, Feilzer A (2004) Influence of fatigue loading on four post-and-core systems in maxillary premolars. Quintessence Int 35:657-667

113. Signore A, Benedicenti S, Kaitsas V, Barone M, Angiero F, Ravera G (2009) Long-term survival of endodontically treated, maxillary anterior teeth restored with either tapered or parallel-sided glass-fiber posts and full-ceramic crown coverage. J Dent 37:115-121 
114. Mannocci F, Pilecki P, Bertelli E, Watson TF (2004) Density of dentinal tubules affects the tensile strength of root dentin. Dent Mater 20:293-296

115. Mannocci F, Ferrari M, Watson TF (1999) Intermittent loading of teeth restored using quartz fiber, carbon-quartz fiber, and zirconium dioxide ceramic root canal posts. J Adhes Dent 1:153-158

116. Phrukkanon S, Burrow MF, Tyas MJ (1999) The effect of dentine location and tubule orientation on the bond strengths between resin and dentine. J Dent 27:265-274

117. Erdemir U, Mumcu E, Topcu FT, Yildiz E, Yamanel K, Akyol M (2010) Micro push-out bond strengths of 2 fiber post types luted using different adhesive strategies. Oral Surg Oral Med Oral Pathol Oral Radiol Endod 110:534-544

118. Bonfante EA, Pegoraro LF, de Goes MF, Carvalho RM (2008) SEM observation of the bond integrity of fiber-reinforced composite posts cemented into root canals. Dent Mater 24:483-491

119. Vermelho PM, Aguiar FH, Reis AF, Giannini M (2011) Bond strength and interfacial ultramorphology of current adhesive systems. J Adhes 87:1148-1166

120. Tay FR, Loushine RJ, Lambrechts P, Weller RN, Pashley DH (2005) Geometric factors affecting dentin bonding in root canals: a theoretical modeling approach. J Endod 31:584-589

doi:10.1186/2196-4351-1-4

Cite this article as: de Moraes et al:: Current concepts on the use and adhesive bonding of glass-fiber posts in dentistry: a review. Applied Adhesion Science 2013 1:4.

\section{Submit your manuscript to a SpringerOpen ${ }^{\circ}$ journal and benefit from:}

- Convenient online submission

Rigorous peer review

- Immediate publication on acceptance

- Open access: articles freely available online

- High visibility within the field

- Retaining the copyright to your article

Submit your next manuscript at $\boldsymbol{\sim}$ springeropen.com 